\title{
The first Korean case of Waardenburg-Shah syndrome with novel endothelin receptor type B mutations
}

\author{
Eun Sun Lee, Jung Min Ko*, and Jin Su Moon \\ Department of Pediatrics, Seoul National University Children's Hospital, Seoul National University College of Medicine, Seoul, Korea
}

\begin{abstract}
Waardenburg syndrome (WS) is a rare genetic disorder, including clinical features of pigmentary abnormalities of irides, skin, hair and sensorineural hearing loss and facial dysmorphism. Among the four types, WS type IV (Waardenburg-Shah syndrome) additionally represents Hirschsprung's disease. Mutations in the SOX10, END3, or EDNRB genes are known to cause WS type IV. Here, we report a 6 year-old girl who was diagnosed as WS type IV by typical clinical manifestations, including skin hypopigmentation, heterochromia of both irides, unilateral sensorineural hearing loss, mild developmental delay and Hirschsprung's disease. The diagnosis was confirmed by molecular genetic analysis of $E D N R B$. Two novel $E D N R B$ mutations were identified, and each mutation was segregated from each of her parents. During the follow-up period, the patient underwent a surgery for spleen torsion and was medically managed due to recurrent enterocolitis. Also, she suffered from impaired immunity including Hirschsprung's associated enterocolitis.
\end{abstract}

Key words: Waardenburg syndrome, Hirschsprung disease, Endothelin B receptor.

\section{Introduction}

Waardenburg syndrome (WS) is a rare genetic disorder which was first described as the association with deafness, depigmentation of the skin, and facial dysmorphism [1]. The prevalence of WS is estimated $1 / 42,000$, and WS accounts for around $2 \%$ of cases of congenital deafness [2]. This syndrome is a kind of neural crest cell disorders caused by mutations in the END3, EDNRB, MITF, PAX3, SNAI2, and SOX10 genes. These genes are commonly involved in the formation and development of several types of cells, including pigment producing cells called melanocytes. Mutations in these genes lead to failure of differentiation in the neural crest, a failure of melanoblasts to migrate, or a failure to terminally differentiate and survive in their final location.

WS is usually classified into four clinical types on the ba- sis of the presence or absence of additional symptoms. Type I (OMIM\# 193500) presents dystopia canthorum. Type II (OMIM\# 193510) has no additional feature, type III (OMIM\# 148820) presents dystopia canthorum and musculoskeletal abnormalities of the upper limbs, and type IV (OMIM\#277580) represents Hirschsprung's disease [3]. Types I and III are caused by mutations in the PAX3 gene. Mutations in the MITF and SNAI2 genes are responsible for type II WS. Mutations in the SOX10, END3, or EDNRB genes cause type IV WS [4]. Among these four types of WS, WS type IV is unique and also known as WS or Hirschsprung's disease type II. Hirschsprung's disease accompanied in WS type IV is a well-known congenital gastrointestinal malformation disorder, which is characterized by the absence of epidermal melanocytes and enteric ganglia leading delayed meconium passage and abdominal distension

\footnotetext{
Received: 12 December 2017, Revised: 18 December 2017, Accepted: 18 December 2017, Published: 31 December 2017

*Corresponding author: Jung Min Ko, M.D., Ph.D.

Department of Pediatrics, Seoul National University Children's Hospital, Seoul National University College of Medicine, 101 Daehak-ro, Jongno-gu, Seoul 03080, Korea.

Tel: +82-2-2072-3570, Fax: +82-2-743-3455, E-mail: jmko@snu.ac.kr

Conflict of interest: The authors declare that they do not have any conflicts of interest.

(c) This is an open-access article distributed under the terms of the Creative Commons Attribution Non-Commercial License (http://creativecommons.org/licenses/by-nc/4.0/) which permits unrestricted non-commercial use, distribution, and reproduction in any medium, provided the original work is properly cited.

(c) Copyright 2017 by the Korean Society of Medical Genetics and Genomics

www.e-kjgm.org
} 
in infancy. The pleiotropic effects of EDNRB and END3 on melanocytes and enteric neurons may present these WS type IV phenotypes [5].

In Korea, there has been no report of WS type IV which was confirmed mutation to date. Here, we report a 6 year-old girl who was diagnosed as WS type IV by typical clinical manifestations including deafness, hypopigmentation, heterochromia of the irides and Hirschsprung's disease, and was confirmed by identification of two novel EDNRB mutations for the first time in Korea.

\section{Case}

A 6 year-old girl was referred to Clinical Genetics Clinic for the molecular diagnosis of WS. She was born with the birth weight of 3,330 $\mathrm{g}$ (50 percentile) at 39 weeks of gestation by uneventful vaginal delivery at a local clinic. Her father and mother were healthy, and there was no evidence of consanguineous marriage. She was the second child and her brother was healthy. Until two days after delivery, she did not pass meconium and suffered from recurrent vomiting after feeding. On the findings of abdominal ultrasonography, ileal atresia was suspected and ileostomy with meconium evacuation was performed at the age of 2 days. However, stool passage was persistently difficult and she underwent subtotal proctocolectomy with ileo-anal anastomosis under the impression of Hirschsprung's disease at the age of 16 days (Fig. 1). Pathology specimen from colon and small bowel resection showed no ganglion cell in the resected tissue and Hirschsprung's disease was confirmed. Beside Hirschsprung's disease, she also had distinct skin features such as bluish irides, blond hair and fair skin color (Fig. 2A). Neonatal hearing screening showed no response in the right ear and comprehensive audiologic examinations revealed sensorineural deafness of the right ear (Fig. 2B). An ophthalmologic examination confirmed the hypopigmented fundus. At the age of 15 months, she was able to walk with support and could speak only two meaningful words. Psychomotor development was delayed for about four months compared to the peers. Chromosome analysis performed at that time showed a normal female karyotype, 46,XX. There was no abnormality in routine laboratory findings including biochemical analyses for inherited metabolic diseases.

Based on the medical history and clinical manifestation, WS type IV was suspected and molecular genetic analysis for SOX10, END3, or EDNRB genes was performed at the age of

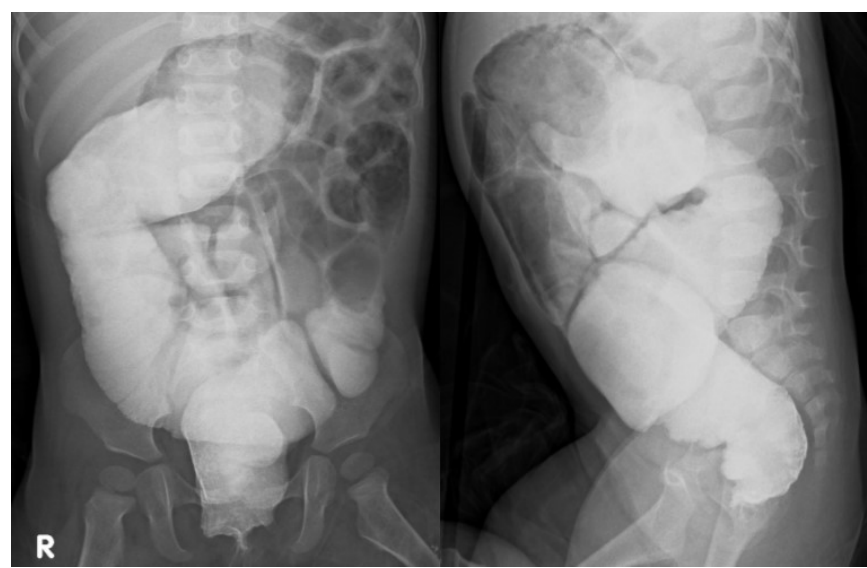

Fig. 1. She underwent total colostomy with Hirschsprung's disease. A colon study was performed at 1 year of age with abdominal distension. In the study, the small bowel was dilatated with feces and fluid.

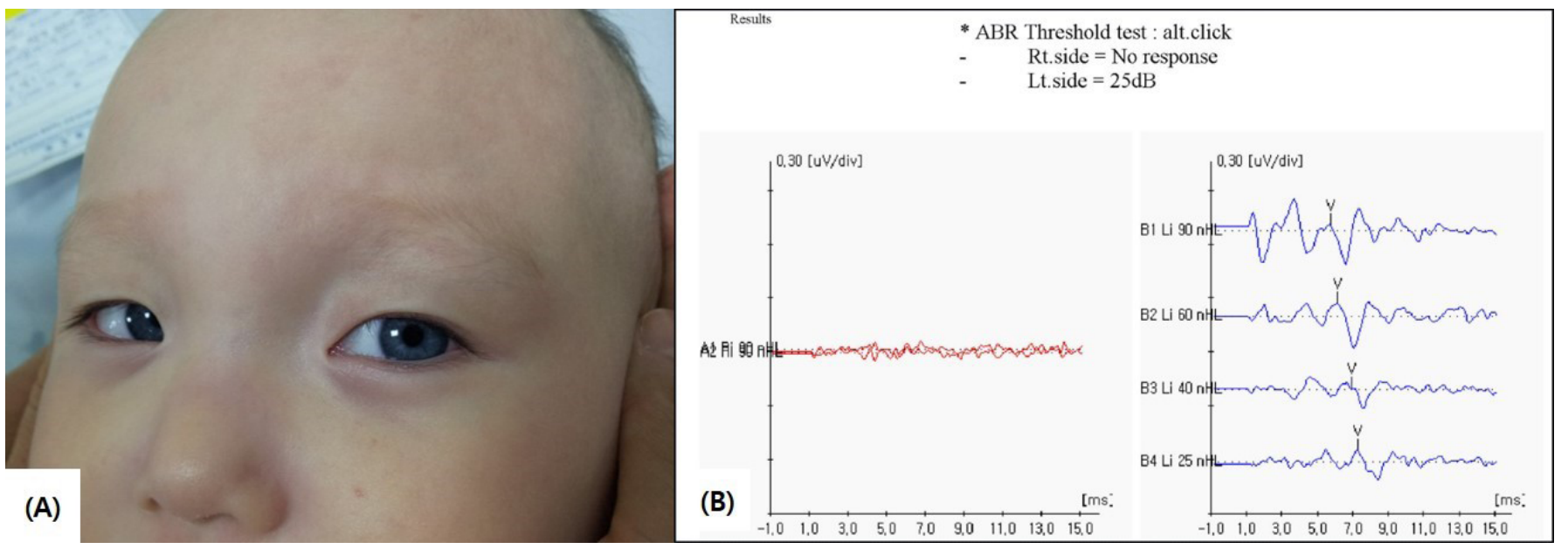

Fig. 2. (A) She had distinct skin features such as heterochromia of irides and fair skin color. (B) Auditory brainstem response threshold test was performed at 1 year of age and the result showed right side sensorineural hearing loss. There was no change in the follow-up examination at the age of 5 years. 

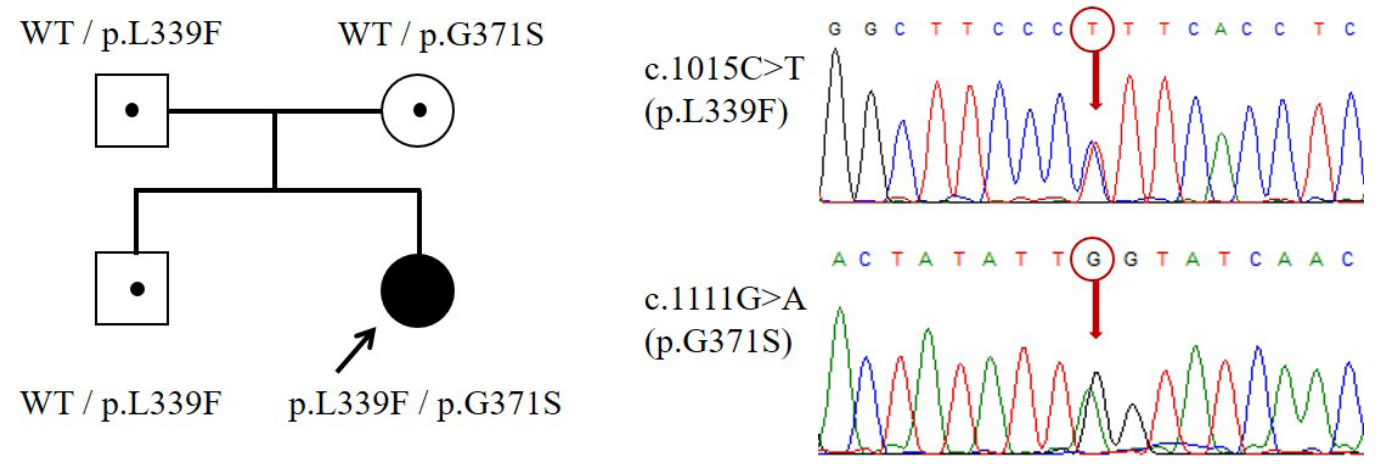

Fig. 3. Partial genomic DNA sequence of the EDNRB gene of the patient. The patient had the following compound heterozygote mutations: c.1015C > T (p.Leu339Phe) and c.1111G>A (p.Gly371Ser). Both of her parents are heterozygous carriers of each mutation.

6 years. Written informed consent to participate in this study was obtained from the patient's parents, and an Institutional Review Board approved the study. Results showed two EDNRB mutations, c. 1015C >T (p.Leu339Phe) and c.1111G >A (p.Gly371Ser), were identified (Fig. 3). From the family screening for these two identified mutations, her father carried c. 1015C>T (p.Leu339Phe) mutation and the mother harbored c.1111G $>A$ (p.Gly371Ser) mutation, respectively. Both of these mutations have not been previously reported. No mutation was found in SOX10 and END3 genes. Therefore, she was confirmatively diagnosed as WS type IV caused by two novel EDNRB mutations compound heterozygously.

After WS type IV diagnosis, she has suffered from recurrent enteritis mimicking clinical features of inflammatory bowel diseases. At the age of five years, she had abdominal pain and bowel distension. Abdominal computed tomography revealed splenic vascular pedicle torsion and splenic infarction. She underwent spleen detorsion operation, and then the spleen perfusion was recovered about twenty percent of the normal value.

\section{Discussion}

WS type IV expresses Hirschsprung's disease with common features for WS including sensorineural deafness, heterochromia of irides, and white forelock [6]. It had previously been known as the autosomal dominant inherited disorder of neural crest cells, however it is now thought that WS type IV is clinically and genetically heterogeneous and that not all forms are dominantly inherited [3]. WS type IV is caused by mutation in the SOX10, END3, or EDNRB genes, and can be classified as three subgroups according to genotypes; type IV A (OMIM\#277580, EDNRB mutation), B (OMIM\#613265, EDN3 mutation), and C (OMIM\#602229, SOX10 mutation).
Mutations in EDNRB or EDN3 genes are found in 20\% to 30\% of WS type IV patients [7]. The EDNRB gene, located in 13q22.3, spans $24 \mathrm{~kb}$ and comprises 7 exons [8]. To date, approximately 60 different mutations have been reported in EDNRB as causes for WS type IV or Hirschsprung's disease (The Human Mutation Database, http://www.hgmd.cf.ac.uk). Our patient was confirmed as WS type IV A due to two EDNRB mutations; c. 1015C > T (p.Leu339Phe) and c. $1111 \mathrm{G}>\mathrm{A}$ (p.Gly371Ser), and each mutation was independently segregated from each of her parents. Although both mutations are novel, they are considered to be pathogenic because they were neither found in ExAC (http:// exac.broadinstitute.org/) nor 1000G databases (http://www. internationalgenome.org/1000-genomes-browsers/), and are located in amino acid residues conserved between different species. In silico analysis programs also indicated that both could affect protein structure and possibly be damaging mutations (SIFT, http://sift.jcvi.org; PolyPhen-2, http://genetics.bwh.harvard.edu/ pph2; Mutation Taster, http://mutationtaster.org).

Even though our patient showed full phenotypes of WS type IV including Hirschsprung's disease, unilateral hearing loss, bluish irises, blond hair and fair skin color because of bialleleic EDNRB mutations, some heterozygous EDNRB mutations of one allele also have been reported in the families with autosomal dominantly inherited WS type IV, isolated Hirschsprung's disease, or pigmentary abnormalities of the skin, hair, and irides, or hearing loss [9-11]. Tuysuz et al. [9] reported variable features of WS IV associated with de novo heterozygous deletions involving chromosome $13 q$ and including the EDNRB gene. The three patients had common facial features consistent with the proximal $13 q$ deletion syndrome and mild developmental delay [12]. However, their clinical phenotypes including hypopigmentation of the irides, hearing loss, and Hirschsprung's disease were discordant between the patients' findings [9], which suggests that there are 
variable expressions observed in patients with heterozygous loss of function mutations in EDNRB.

Our patient had mild developmental delay additionally. The neurodevelopmental problem of WS type IV caused by sequence variants in $E D N R B$ is not known clearly yet, even if the previous reported cases with $13 q$ deletion including EDNRB understandably accompanied delayed neuropsychiatric development $[9,13]$. Moreover, our patient suffered from recurrent enterocolitis mimicking inflammatory bowel diseases after surgeries for Hirschsprung's disease and underwent another operation for spleen torsion. Although these symptoms are not typical of WS type IV, this finding can be explained by the association of EDNRB mutations and immune dysfunction. Hirschsprung's associated enterocolitis is a condition with manifestation that include fever, abdominal distension, and foul-smelling stool [14]. Up to $40 \%$ of Hirschsprung's disease patients suffer recurrent enterocolitis due to impaired gastrointestinal mucosal immunity. From the EDNRB knockout animal study, neural crest cell migration may also be involved in the development of secondary lymphoid organs. The animals display reduced splenic size, abnormal splenic architecture, reduced total lymphocytes in the spleen and decreased production of immunoglobulin A in the gut [15]. It may be possible that the spleen torsion of our patient is related to altered endothelin receptor type $B$ function due to EDNRB mutations. Also, in patients with Hirschsprung's disease, altered goblet cell structures and functions in aganglionic segments of bowel may be responsible for the recurrent enterocolitis [16]. The complex interactions between EDNRB mutations, immune dysfunction, and changes in gut functional conditions due to Hirschsprung's disease could be associated with recurrent enteritis shown in our patient.

In conclusion, our patient had WS type IV with two novel heterozygous mutations of the EDNRB gene, and this is the first WS type IV case report in Korea. She showed typical phenotypes of WS type IV such as Hirschsprung's disease, unilateral hearing loss, bluish irises, blond hair and fair skin color as well as uncommon phenotypes including impaired immune functions, abnormal splenic architecture, and delayed development.

\section{References}

1. Waardenburg PJ. A new syndrome combining developmental anomalies of the eyelids, eyebrows and nose root with pigmentary defects of the iris and head hair and with congenital deafness. Am J Hum Genet 1951;3:195-253.

2. Nayak CS, Isaacson G. Worldwide distribution of Waardenburg syn- drome. Ann Otol Rhinol Laryngol 2003;112:817-20.

3. Pingault V, Ente D, Dastot-Le Moal F, Goossens M, Marlin S, Bondurand N. Review and update of mutations causing Waardenburg syndrome. Hum Mutat 2010;31:391-406.

4. Sharma K, Arora A. Waardenburg syndrome: a case study of two patients. Indian J Otolaryngol Head Neck Surg 2015;67:324-8.

5. McCallion AS, Chakravarti A. EDNRB/EDN3 and Hirschsprung disease type II. Pigment Cell Res 2001;14:161-9.

6. Shah KN, Dalal SJ, Desai MP, Sheth PN, Joshi NC, Ambani LM. White forelock, pigmentary disorder of irides, and long segment Hirschsprung disease: possible variant of Waardenburg syndrome. J Pediatr 1981;99:432-5.

7. Doubaj Y, Pingault V, Elalaoui SC, Ratbi I, Azouz M, Zerhouni $H_{\text {, et al }}$ A novel mutation in the endothelin $B$ receptor gene in a moroccan family with shah-waardenburg syndrome. Mol Syndromol 2015;6:449.

8. Arai H, Nakao K, Takaya K, Hosoda K, Ogawa Y, Nakanishi S, et al. The human endothelin-B receptor gene. Structural organization and chromosomal assignment. J Biol Chem 1993;268:3463-70.

9. Tüysüz $B$, Collin $A$, Arapoğlu M, Suyugül N. Clinical variability of Waardenburg-Shah syndrome in patients with proximal $13 q$ deletion syndrome including the endothelin-B receptor locus. Am J Med Genet A 2009;149A:2290-5.

10. Puffenberger EG, Kauffman ER, Bolk S, Matise TC, Washington SS, Angrist $\mathrm{M}_{\text {, et }}$ al. Identity-by-descent and association mapping of a recessive gene for Hirschsprung disease on human chromosome 13q22. Hum Mol Genet 1994;3:1217-25.

11. Sangkhathat $S$, Chiengkriwate $P$, Kusafuka T, Patrapinyokul S, Fukuzawa M. Novel mutation of Endothelin-B receptor gene in Waardenburg-Hirschsprung disease. Pediatr Surg Int 2005;21:960-3.

12. Brown S, Gersen S, Anyane-Yeboa K, Warburton D. Preliminary definition of a "critical region" of chromosome 13 in q32: report of 14 cases with $13 q$ deletions and review of the literature. Am J Med Genet 1993;45:52-9.

13. Garcia-Rodriguez E, Garcia-Garcia E, Perez-Sanchez A, PavonDelgado A. A new observation of $13 q$ deletion syndrome: severe undescribed features. Genet Couns 2015;26:213-7.

14. Demehri FR, Halaweish IF, Coran AG, Teitelbaum DH. Hirschsprungassociated enterocolitis: pathogenesis, treatment and prevention. Pediatr Surg Int 2013;29:873-81.

15. Gosain A, Barlow-Anacker AJ, Erickson CS, Pierre JF, Heneghan AF, Epstein $\mathrm{ML}$, et al. Impaired cellular immunity in the murine neural crest conditional deletion of endothelin receptor-B model of Hirschsprung's disease. PLoS One 2015;10:e0128822.

16. Gosain A, Brinkman AS. Hirschsprung's associated enterocolitis. Curr Opin Pediatr 2015;27:364-9. 